\title{
Burnout and job satisfaction of psychiatrists in China: a nationwide survey
}

Hao Yao ${ }^{1 \dagger}$, Peicheng Wang ${ }^{2,3+}$, Yi-Lang Tang ${ }^{4,5}$, Yuanli Liu' ${ }^{6}$, Tingfang Liu ${ }^{7}$, Huanzhong Liu ${ }^{8,9}$, Yanhua Chen ${ }^{2,3}$, Feng Jiang ${ }^{10^{*}+}$ and Jiming Zhu ${ }^{2^{*} \dagger}$

\begin{abstract}
Background: Despite a significant shortage of psychiatrists in China, an ever-increasing number of psychiatrists in China are experiencing burnout and job dissatisfaction and considering leaving their jobs. Yet, to our knowledge, there have been no nationwide studies to date that examined both burnout and job dissatisfaction of psychiatrists in China. Therefore, this study evaluated burnout and job dissatisfaction of psychiatrists in China, and identified relevant characteristics.
\end{abstract}

Methods: We conducted a nationwide, cross-sectional survey in March 2019. Psychiatrists from all tertiary psychiatric hospitals in China were invited to participate. The Maslach Burnout Inventory-Human Service Survey and the short version of the Minnesota Satisfaction Questionnaire were used to measure burnout and job satisfaction. Data on sociodemographic and occupational characteristics were collected. Multivariate logistic regression was conducted to identify socio-demographic and occupational characteristics associated with burnout and job satisfaction.

Results: In total, 4520 psychiatrists from tertiary psychiatric hospitals in China completed the questionnaire. Overall, $38.4 \%$ of respondents met the criteria for burnout and $35.6 \%$ were dissatisfied with their jobs. Being male, more years of practice, having no leadership role, and longer working hours per week were significantly associated with burnout and job dissatisfaction. Lower monthly pay was significantly associated with job dissatisfaction but not burnout. Moreover, burnout was significantly associated with job dissatisfaction.

Conclusions: Our data suggest a high rate of burnout and job dissatisfaction among psychiatrists in China. In order to preserve and strengthen the mental health workforce, proactive measures are urgently needed to mitigate burnout and job dissatisfaction among psychiatrists in China.

Keywords: Burnout, Job satisfaction, Psychiatrists, China

\section{Background}

With an estimated 173 million people living with mental disorders currently in China [1], China accounts for the largest percentage $(17 \%)$ of the global mental, neurological, and substance use disorder burden [2].

\footnotetext{
* Correspondence: jimingzhu@tsinghua.edu.cn

${ }^{\dagger} \mathrm{Hao}$ Yao and Peicheng Wang were joint first authors. Feng Jiang and Jiming Zhu were joint corresponding authors.

${ }^{10}$ School of International and Public Affairs, Shanghai Jiao Tong University, Shanghai, China

${ }^{2}$ Vanke School of Public Health, Tsinghua University, Beijing 100084, China Full list of author information is available at the end of the article
}

According to the latest nationwide survey of mental disorders in China, the lifetime prevalence of any mental disorder has increased significantly from $1.3 \%$ in 1982 to $16.6 \%$ in 2015 [3]. Moreover, since the outbreak of the COVID-19 epidemic, it was suggested that Chinese mental health burden has further escalated $[4,5]$. One nationally representative study showed that the prevalence of anxiety or depression or both was as high as $20.4 \%$ among the general adult population in China at the peak of the COVID-19 epidemic [6]. Not only do mental disorders have high personal costs for patients

C C The Author(s). 2021 Open Access This article is licensed under a Creative Commons Attribution 4.0 International License, which permits use, sharing, adaptation, distribution and reproduction in any medium or format, as long as you give appropriate credit to the original author(s) and the source, provide a link to the Creative Commons licence, and indicate if changes were made. The images or other third party material in this article are included in the article's Creative Commons licence, unless indicated otherwise in a credit line to the material. If material is not included in the article's Creative Commons licence and your intended use is not permitted by statutory regulation or exceeds the permitted use, you will need to obtain permission directly from the copyright holder. To view a copy of this licence, visit http://creativecommons.org/licenses/by/4.0/ The Creative Commons Public Domain Dedication waiver (http://creativecommons.org/publicdomain/zero/1.0/) applies to the data made available in this article, unless otherwise stated in a credit line to the data. 
and caregivers, but they also have high social and economic costs for the entire society. It was estimated that the year 2013 witnessed a total annual cost of $\$ 88.8$ billion attributed to mental disorders in China, which was nearly four times that in 2005 [7].

Evidently, China is now faced with a surging demand for mental health service provision among the general population. However, a severe shortage of psychiatrists poses a major challenge to China's mental health care system. Nowadays, the total number of psychiatrists in China is just above 40,000 [8], indicating that there are less than 3 psychiatrists per 100,000 population. Moreover, most of these psychiatrists are working in the more socioeconomically developed eastern coastal region of China, leaving the treatment gap for mental disorders in China's western and central regions strikingly huge [810]. In order to develop and strengthen the mental health workforce in China, the General Office of China's State Council issued the 2015-2020 National Mental Health Work Plan [11] in 2015 which proposed a package of measures to develop and strengthen the mental health workforce in China, including encouraging regions and higher education institutions to provide medical bachelor's degrees specializing in psychiatry, allowing non-psychiatrist physicians to switch their clinical specialties to psychiatry after receiving training in psychiatry, and improving the level of remuneration for mental health professionals. However, the effectiveness of these measures has been inadequately evaluated and the number of psychiatrists in China is still far less than needed [10]. In addition, most of these efforts till now have been focused on recruiting more psychiatrists, with the retention issues of psychiatrists largely neglected. In fact, it was reported that an ever-increasing amount of psychiatrists in China are experiencing occupational burnout which further leads to job dissatisfaction [12] and intent to leave their jobs [13].

As defined by the World Health Organization [14], burnout is "a syndrome conceptualized as resulting from chronic workplace stress that has not been successfully managed." It is characterized by three dimensions: emotional exhaustion (EE), depersonalization (DP), and reduced personal accomplishment (PA) [15]. Numerous studies have reported a high rate of burnout among physicians [16-18]. A number of socio-demographic and occupational factors appear to relate to physician burnout. For example, high workloads, lack of job control, poor work-life balance, and loss of support from colleagues have each been associated with physician burnout [1924]. Some studies have reported an increased risk of burnout among younger physicians [24-26]. Female physicians also seem to be more likely to experience burnout than their male counterparts [27-29]. It is indicated that burnout has grave repercussions on physicians' physical and mental health and well-being $[19,30]$, as well as their job performance [31-33]. More importantly, physicians experiencing burnout are more likely to be dissatisfied with their jobs and to consider leaving [34-36], which in turn threatens health workforce retention particularly in low- and middle-income countries (LMICs) with limited human resources for health. Burnout among psychiatrists has also been documented in many countries [37-41]. For example, 36.9\% of psychiatrists in the US showed burnout symptoms in 2017 [17]; the prevalence rate of burnout among psychiatrists in Japan was $40 \%$ in 2016 [42]. However, most studies of burnout among psychiatrists to date were conducted in high-income countries (HICs) [43], leaving an evidence gap with regards to burnout among psychiatrists in LMICs.

In China, a vast majority $(\sim 80 \%)$ of psychiatrists are working at psychiatric hospitals, whereas those working at other mental health service providers, such as general hospitals, rehabilitation hospitals, and community health centers, account for only a small percentage [8]. Psychiatric hospitals in China can be further classified into two tiers: secondary psychiatric hospitals (SPHs), which tend to be affiliated with a medium size city, county or district; and tertiary psychiatric hospitals (TPHs), which are often situated in provincial capitals or major cities. In the absence of a well-developed referral system, people with mental health conditions in China have the freedom to choose where they want to obtain specialist mental health services from, and most of them prefer TPHs [44]. Moreover, in addition to providing specialist mental health services for larger geographical areas than SPHs, TPHs are also responsible for providing guidance and support to all other mental health service providers, including SPHs, in the corresponding areas [45]. Therefore, Chinese psychiatrists working at TPHs are often burdened with much heavier workloads and faced with an even grimmer crisis of burnout $[46,47]$.

Given the importance of burnout and job dissatisfaction to workforce retention and the central role that TPHs play in China's mental health care system, there is a strong imperative to investigate the prevalence of burnout and job dissatisfaction among psychiatrists at TPHs in China, as well as the risk factors for burnout and job dissatisfaction. Yet, to our knowledge, there have been no nationwide studies in China to date that have achieved these purposes. Therefore, this nationwide study aimed to investigate the prevalence of burnout and job dissatisfaction among psychiatrists at TPHs in China, to identify sociodemographic and occupational factors associated with burnout and job dissatisfaction, and to examine the 
relationship between burnout and job dissatisfaction among psychiatrists.

\section{Methods \\ Study design and participants}

We conducted a nationwide, cross-sectional survey in March 2019 to investigate the prevalence of burnout and job dissatisfaction among psychiatrists at TPHs in China. All psychiatrists $(n=6986)$ from 41 TPHs in China were invited to participate in our survey. In total, there were 40,435 psychiatrists in China by the end of 2018, so approximately one sixth psychiatrists in China were included in our survey. To cover all the psychiatrists working at TPHs in China, we collaborated with each province's Health Commission to issue a notice about this survey to all the TPHs situated in the corresponding province, and then the hospital administrators of these TPHs organized and facilitated the psychiatrists working at their hospitals to participate in this survey. Each psychiatrist completed a smartphone-based questionnaire anonymously and voluntarily throughout the process. All research data were de-identified and stored in a secure way to protect confidentiality. The research protocol was approved by the Ethics Committee of Chaohu Hospital of Anhui Medical University (No.201903-kyxm-02) and an electronic consent form was obtained from each participant.

\section{Questionnaires}

The questionnaire consisted of three parts. Clear instructions were provided to participants before each section. Part 1 involved socio-demographic and occupational characteristics, i.e., age, gender (male or female), marital status (single, married, or other), site of practice (Eastern China, Central China, Western China, and Northeast China), years of practice, monthly pay in previous year, working hours per week, and having a leadership role or not.

In Part 2, the Maslach Burnout Inventory-Human Service Survey (MBI-HSS) [48] was used to measure burnout among psychiatrists in China. The Chinese version of MBI-HSS has already been validated in many studies [49-51]. It is a 22-item scale scoring the following three domains of burnout: emotional exhaustion (EE), involving nine items; depersonalization (DP), involving five items; and reduced personal accomplishment (PA), involving eight items. These items are scored on a 7-point scale from 0 to 6 according to the frequency of symptoms. Participants with high EE $(\geq 27)$ or DP $(\geq 10)$ scores were defined as having burnout [50, 52-55]. In our study, the Chinese version of MBI-HSS had sound face and content validity and the Cronbach's alpha was 0.838 .

In Part 3, the short version of the Minnesota Satisfaction Questionnaire (MSQ) was used to measure job satisfaction among psychiatrists in China. The Chinese version of MSQ has been widely used and demonstrated sound reliability and validity $[56,57]$. MSQ has twenty items scored on a 5-point scale ranging from 1, very dissatisfied, to 5, very satisfied. The average score of these twenty items was calculated for each participant and participants with an average score of $\geq 3$ were defined as being satisfied with their jobs in general [58]. In addition, MSQ includes two subscales: (1) intrinsic job satisfaction, which refers to whether people feel satisfied with the factors related to the nature of their jobs; and (2) extrinsic job satisfaction, which refers to whether people feel satisfied with the factors related to the working conditions that are external to their jobs [59]. The subscale scores were calculated as the average scores of subscale items, and participants with an average subscale score of $\geq 3$ were defined as being satisfied with intrinsic or extrinsic factors of their jobs. The Chinese version of MSQ demonstrated sound reliability in our study, with the Cronbach's alpha being 0.952 .

\section{Statistical analysis}

Continuous variables with normal distribution were reported as mean (standard deviation [SD]), and differences between groups were compared using t-tests. Continuous variables with skewed distribution were reported as median (interquartile range [IQR]) and compared using the Mann-Whitney $U$ test. Categorical variables were presented as the number (percentage) and compared using chi-square test or unidirectional ordered chi-square test. Multivariate logistic regression was conducted to explore potential risk factors of burnout and job satisfaction. Odds ratios (ORs) for different variables and corresponding 95\% confidence intervals (CIs) were reported. Statistical analyses were performed using SAS 9.4 (SAS Institute, Cary, NC, USA). Two-tailed $p$ values of less than 0.05 were considered statistically significant.

\section{Results \\ Socio-demographic and occupational characteristics of respondents}

In total, there were 6986 psychiatrists working at 41 TPHs in China in 2019, and they were all invited to participate in this study. Of them, 4520 psychiatrists completed the questionnaire (completion rate, 64.7\%). Table 1 shows data on their socio-demographic and occupational characteristics. 2626 respondents (58.1\%) were female, and 2207 (48.8\%) were aged between 30 and 39. Most respondents (81.2\%) were married. About two thirds had a bachelor's degree or less. 992 respondents $(44.5 \%)$ had been practicing psychiatry for less than 5 years. 954 respondents (21.1\%) had leadership roles in their workplaces, with males more likely $(28.7 \%$; $543 / 1892$ vs $15.6 \% ; 1349 / 2628 ; P<.001)$. The median 
Table 1 Socio-demographic and occupational characteristics of 4520 psychiatrists in China who participated in the study, n(\%)

\begin{tabular}{|c|c|c|c|c|}
\hline Characteristic & All $(n=4520)$ & Male $(n=1892)$ & Female $(n=2628)$ & $\mathbf{P}$ \\
\hline \multicolumn{5}{|l|}{ Gender } \\
\hline Male & $1892(41.9)$ & - & - & - \\
\hline Female & $2628(58.1)$ & - & - & - \\
\hline \multicolumn{5}{|l|}{ Site of practice } \\
\hline Eastern China & $1631(36.1)$ & $653(34.5)$ & 978 (37.2) & \multirow[t]{4}{*}{.003} \\
\hline Central China & $948(21.0)$ & $423(22.4)$ & $525(20.0)$ & \\
\hline Western China & $1197(26.5)$ & $472(24.9)$ & $725(27.6)$ & \\
\hline Northeast China & $744(16.5)$ & $344(18.2)$ & $400(15.2)$ & \\
\hline \multicolumn{5}{|l|}{ Age, years } \\
\hline$\leq 29$ & $602(13.3)$ & $163(8.6)$ & $439(16.7)$ & \multirow[t]{4}{*}{$<.001$} \\
\hline $30-39$ & 2207 (48.8) & $844(44.6)$ & $1363(51.9)$ & \\
\hline $40-49$ & $1082(23.9)$ & $510(27.0)$ & $572(21.8)$ & \\
\hline$\geq 50$ & $629(13.9)$ & $375(19.8)$ & $254(9.7)$ & \\
\hline \multicolumn{5}{|l|}{ Marital status } \\
\hline Married & $3668(81.2)$ & $1610(85.1)$ & $2058(78.3)$ & \multirow[t]{3}{*}{$<.001$} \\
\hline Single & $690(15.3)$ & $221(11.7)$ & $469(17.8)$ & \\
\hline Other & $162(3.6)$ & $61(3.2)$ & $101(3.8)$ & \\
\hline \multicolumn{5}{|l|}{ Education } \\
\hline Associate degree or less & $123(2.7)$ & $69(3.6)$ & $54(2.1)$ & \multirow[t]{4}{*}{$<.001$} \\
\hline Bachelor's degree & $2866(63.4)$ & $1287(68.0)$ & $1579(60.1)$ & \\
\hline Master's degree & $1257(27.8)$ & $425(22.5)$ & $832(31.7)$ & \\
\hline Doctorate degree & $274(6.1)$ & $111(5.9)$ & $163(6.2)$ & \\
\hline \multicolumn{5}{|l|}{ Years of practice, years } \\
\hline$\leq 5$ & $992(21.9)$ & $308(16.3)$ & $684(26.0)$ & \multirow[t]{4}{*}{$<.001$} \\
\hline $6-10$ & $1023(22.6)$ & $358(18.9)$ & $665(25.3)$ & \\
\hline $11-20$ & $1405(31.1)$ & $634(33.5)$ & $771(29.3)$ & \\
\hline$\geq 21$ & $1100(24.3)$ & $592(31.3)$ & $508(19.3)$ & \\
\hline \multicolumn{5}{|l|}{ Leadership role } \\
\hline Yes & $954(21.1)$ & $543(28.7)$ & $1349(15.6)$ & \multirow[t]{2}{*}{$<.001$} \\
\hline No & $3566(78.9)$ & $411(71.3)$ & $2217(84.4)$ & \\
\hline \multicolumn{5}{|c|}{ Monthly pay in previous year, $\mathrm{RMB}^{\mathrm{a}}$} \\
\hline$<5000$ & $720(16.5)$ & $278(14.7)$ & $442(16.8)$ & \multirow[t]{4}{*}{$<.001$} \\
\hline 5000-7999 & $1604(36.7)$ & $636(33.6)$ & $968(36.8)$ & \\
\hline $8000-11,999$ & $1395(31.9)$ & $615(32.5)$ & $780(29.7)$ & \\
\hline$\geq 12,000$ & $649(14.9)$ & $310(16.4)$ & $339(12.9)$ & \\
\hline \multicolumn{5}{|c|}{ Working hours per week, hours } \\
\hline$\leq 40$ & $261(5.8)$ & $124(6.6)$ & $137(5.2)$ & \multirow[t]{4}{*}{.026} \\
\hline $41-50$ & $1976(43.7)$ & $794(42.0)$ & $1182(45.0)$ & \\
\hline $51-60$ & $781(17.3)$ & 314 (16.6) & 467 (17.8) & \\
\hline$\geq 61$ & 1502 (33.2) & 660 (34.9) & 842 (32.0) & \\
\hline
\end{tabular}

a. Ratio of US dollar to Chinese yuan (RMB) $=6.47$ 
(IQR) monthly pay of our sample was 7000 (5000$10,000) \mathrm{RMB}$, and males reported significantly higher monthly pay compared with their female counterparts $(P=.003)$. The mean (SD) working hours per week was 53.0 (16.1) hours, with 4259 (94.2\%) reporting for more than $40 \mathrm{~h}$ per week, and males reported significantly longer working hours than their female counterparts $(P=$ .012).

\section{Prevalence of burnout and job dissatisfaction}

Table 2 shows data on burnout and job dissatisfaction in our sample. $1146(25.4 \%)$ respondents reported a high level of EE, 1485 (32.9\%) reported a high level of DP, and $935(20.7 \%)$ reported a low level of PA. Overall, 1735 (38.4\%) respondents met the criteria of burnout. Moreover, males in our sample had a slightly higher rate of burnout (39.6\%; 750/1892) compared with females (37.5\%; 985/2628), but the difference was not statistically significant $(P=.141)$.

Overall, 1609 respondents (35.6\%) were dissatisfied with their jobs in general, and males reported a higher rate of general job dissatisfaction than females (59.6\%;

Table 2 Prevalence of burnout and job satisfaction in a sample of 4520 psychiatrists in China, $\mathrm{n}(\%)$

\begin{tabular}{|c|c|c|c|c|}
\hline & All $(n=4520)$ & Male $(n=1892)$ & Female $(n=2628)$ & $\mathbf{P}$ \\
\hline \multicolumn{5}{|l|}{ Burnout } \\
\hline Yes & 1735 (38.4) & $750(39.6)$ & $985(37.5)$ & \multirow[t]{2}{*}{.141} \\
\hline No & 2785 (61.6) & $1142(60.4)$ & $1643(62.5)$ & \\
\hline \multicolumn{5}{|c|}{ Emotional exhaustion } \\
\hline Low & $2419(53.5)$ & 1019 (53.9) & $1400(53.3)$ & \multirow[t]{3}{*}{.634} \\
\hline Mid & $955(21.1)$ & 387 (20.5) & $568(21.6)$ & \\
\hline High & $1146(25.4)$ & $486(25.7)$ & $660(25.1)$ & \\
\hline \multicolumn{5}{|c|}{ Depersonalization } \\
\hline Low & $1538(34.0)$ & $606(32.0)$ & $932(35.5)$ & \multirow[t]{3}{*}{.029} \\
\hline Mid & $1497(33.1)$ & $630(33.3)$ & $867(33.0)$ & \\
\hline High & $1485(32.9)$ & $656(34.7)$ & $829(31.5)$ & \\
\hline \multicolumn{5}{|c|}{ Personal accomplishment } \\
\hline Low & $2555(56.5)$ & $1099(58.1)$ & $1456(55.4)$ & \multirow[t]{3}{*}{.146} \\
\hline Mid & $1030(22.8)$ & $407(21.5)$ & $623(23.7)$ & \\
\hline High & $935(20.7)$ & $386(20.4)$ & $549(20.9)$ & \\
\hline \multicolumn{5}{|c|}{ General Job Satisfaction } \\
\hline Yes & $2911(64.4)$ & $1127(59.6)$ & $1784(67.9)$ & \multirow[t]{2}{*}{$<.001$} \\
\hline No & 1609 (35.6) & $765(40.4)$ & $844(32.1)$ & \\
\hline \multicolumn{5}{|c|}{ Intrinsic Job Satisfaction } \\
\hline Yes & $3136(69.4)$ & $1212(64.1)$ & $1924(73.2)$ & \multirow[t]{2}{*}{$<.001$} \\
\hline No & 1384 (30.6) & $680(35.9)$ & $704(26.8)$ & \\
\hline \multicolumn{5}{|c|}{ Extrinsic Job Satisfaction } \\
\hline Yes & $2362(52.3)$ & $983(52.0)$ & $1175(44.7)$ & \multirow[t]{2}{*}{$<.001$} \\
\hline No & $2158(47.7)$ & $909(48.0)$ & $1453(55.3)$ & \\
\hline
\end{tabular}

$765 / 1892$ vs $67.9 \% ; 844 / 2628 ; P<.001)$. Interestingly, males were more likely to be dissatisfied with intrinsic factors of their jobs than females $(35.9 \%$; $680 / 1892$ vs $26.8 \%$; 704/2628; $\mathrm{P}<.001)$ but less likely to be dissatisfied with extrinsic factors than females (48.0\%; 909/1892 vs $55.3 \%$; $1454 / 2628 ; \mathrm{P}<.001)$.

\section{Factors associated with burnout and job dissatisfaction}

We examined the associations between respondent characteristics and burnout (Table 3, also see Supplementary Table 1 in Additional File 1). It was found that being male (OR 1.20, 95\% CI 1.05-1.37), 11-20 years of practice (OR 1.42, 95\% CI 1.10-1.84; reference: $\leq 5$ years), having no leadership role (OR 1.60, 95\% CI 1.32$1.95)$, and longer working hours per week $(41-50 \mathrm{~h}$ : OR 1.47 , 95\% CI 1.08-2.01; 51-60 h: OR 2.39, 95\% CI $1.71-$ $3.34 ; \geq 61$ h: OR $3.09,95 \%$ CI 2.25-4.25; reference: $\leq 40$ h) were significantly associated with burnout. There were no significant associations between monthly pay and burnout (5000-7999 RMB: OR 0.90, 95\% CI 0.74-1.09; 8000-11,999 RMB: OR 0.88, 95\% 0.71-1.10; $\geq 12,000$ RMB: OR 0.77, 95\% CI 0.58-1.03; reference: <5000 RMB) after adjusting for other variables.

The associations between socio-demographic characteristics and job satisfaction were also examined (Table 3, also see Supplementary Table 2 in Additional File 1). It was found that being male (OR 0.66, 95\% CI $0.58-$ 0.76), working in Northeast China (OR 1.29, 95\% CI 1.03-1.61; reference: Eastern China), more years of practice $(6-10$ years: OR $0.77,95 \%$ CI $0.6-0.98 ; 11-20$ years: OR $0.56,95 \%$ CI $0.43-0.73$; $\geq 21$ years: OR $0.58,95 \% \mathrm{CI}$ 0.4-0.85; reference: $\leq 5$ years), having no leadership role (OR 0.54, 95\% CI 0.44-0.65), lower monthly pay (800011,999 RMB: OR 1.50, 95\% CI 1.20-1.87; $\geq 12,000$ RMB: OR 1.92, 95\% CI 1.44-2.56; reference: $<5000 \mathrm{RMB}$ ), and longer working hours per week (51-60 h: OR 0.70, 95\% CI $0.51-0.96$; $\geq 61 \mathrm{~h}$ : OR $0.60,95 \%$ CI $0.44-0.81$; reference: $\leq 40 \mathrm{~h}$ ) were significantly associated with job dissatisfaction in general.

\section{Relationship between burnout and job satisfaction}

The prevalence of job satisfaction among respondents with and without burnout is shown in Fig. 1. Seven hundred fifty respondents (43.2\%) with burnout were satisfied with their jobs in general, while 2140 respondents $(77.6 \%)$ without burnout were satisfied. As shown in Table 4, burnout was negatively associated with general job satisfaction (OR $0.23,95 \%$ CI $0.20-0.26, P<.001$ ), after adjustment for gender, age, marital status, education, site of practice, years of practice, having a leadership role or not, monthly pay, and working hours per week. Similarly, respondents with burnout were significantly more likely to report dissatisfaction with intrinsic factors of their jobs (OR $0.25,95 \%$ CI $0.21-0.28$, 
Table 3 Effects of respondent characteristics on burnout and general job satisfaction in a sample of 4520 psychiatrists in China

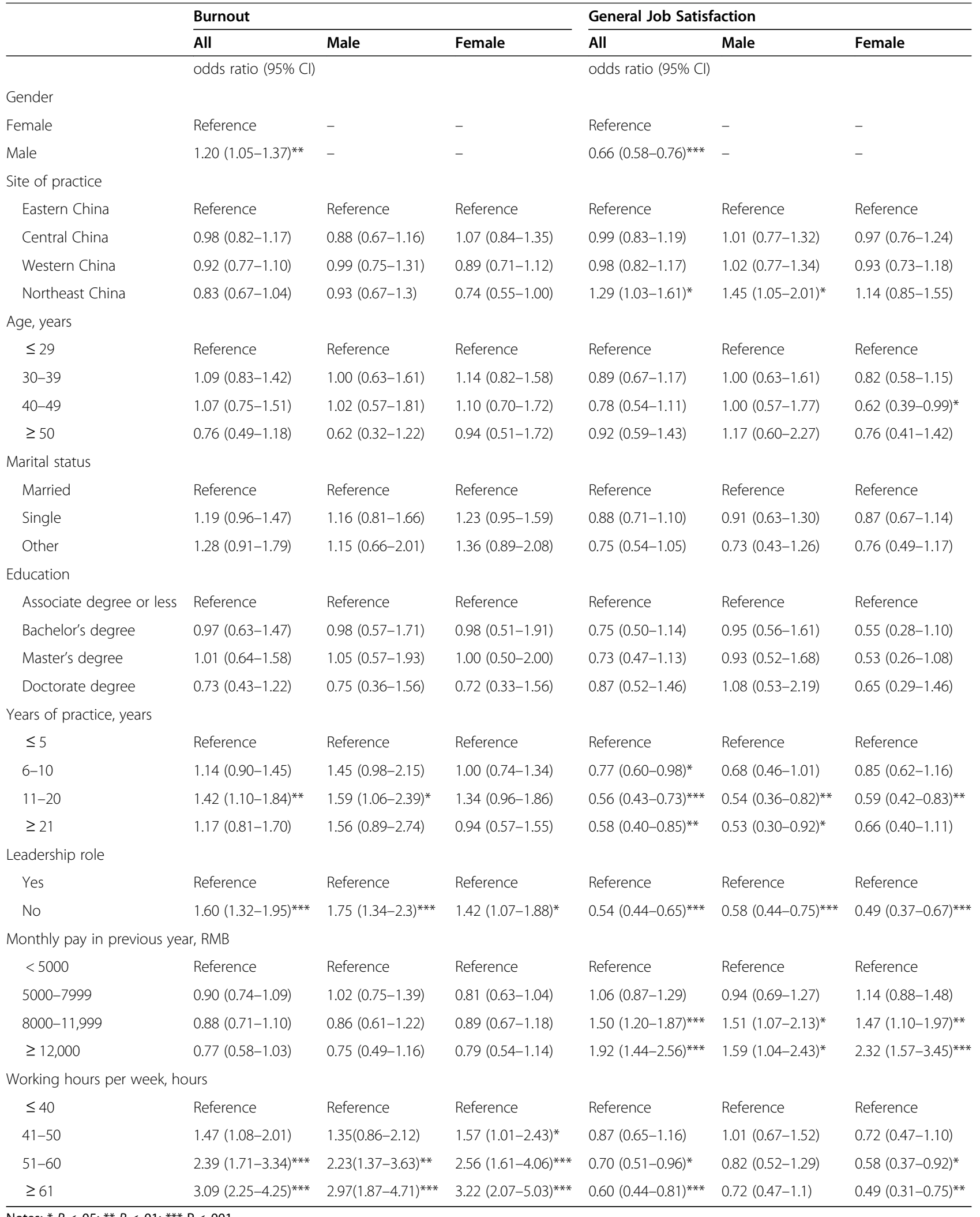




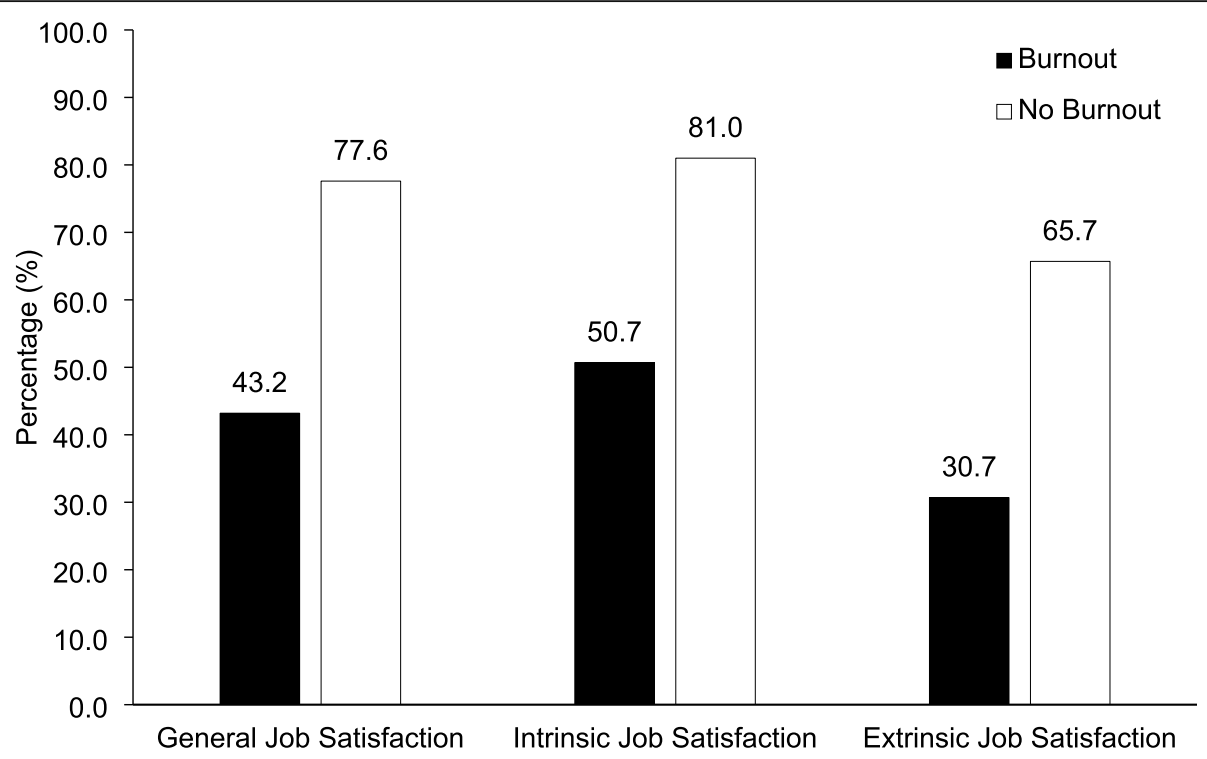

Fig. 1 Prevalence of job satisfaction among respondents with or without burnout in a sample of 4520 psychiatrists in China

Table 4 Effects of burnout on job satisfaction in a sample of 4520 psychiatrists in China

\begin{tabular}{|c|c|c|c|c|c|c|c|c|}
\hline \multicolumn{9}{|c|}{ Job Satisfaction } \\
\hline \multicolumn{3}{|c|}{ General Job Satisfaction } & \multicolumn{3}{|c|}{ Intrinsic Job Satisfaction } & \multicolumn{3}{|c|}{ Extrinsic Job Satisfaction } \\
\hline$A \|^{a}$ & Male ${ }^{b}$ & Female $^{b}$ & $A \|^{a}$ & Male $^{b}$ & Female $^{b}$ & $\mathrm{All}^{\mathrm{a}}$ & Male ${ }^{b}$ & Female \\
\hline \multicolumn{3}{|c|}{ odds ratio (95\% Cl) } & \multicolumn{3}{|c|}{ odds ratio $(95 \% \mathrm{Cl})$} & \multicolumn{3}{|c|}{ odds ratio $(95 \% \mathrm{Cl})$} \\
\hline
\end{tabular}

Burnout

$\begin{array}{llllllllll}\text { No } & \text { Reference } & \text { Reference } & \text { Reference } & \text { Reference } & \text { Reference } & \text { Reference } & \text { Reference } & \text { Reference } & \text { Reference } \\ \text { Yes } & 0.23(0.20- & 0.23(0.19- & 0.22(0.18- & 0.25(0.21- & 0.23(0.18- & 0.25(0.21- & 0.25(0.22- & 0.25(0.21- & 0.24(0.2-0.30) \\ & 0.26) & 0.29) & 0.26) & 0.28) & 0.28) & 0.30) & 0.29) & 0.31) & \end{array}$

Emotional exhaustion

$\begin{array}{llllllllll}\text { Low } & \text { Reference } & \text { Reference } & \text { Reference } & \text { Reference } & \text { Reference } & \text { Reference } & \text { Reference } & \text { Reference } & \text { Reference } \\ \text { Mid } & 0.33(0.28- & 0.35(0.27- & 0.32(0.26- & 0.33(0.28- & 0.34(0.26- & 0.32(0.25- & 0.38(0.32- & 0.38(0.29- & 0.39(0.30- \\ & 0.4) & 0.45) & 0.41) & 0.38) & 0.44) & 0.39) & 0.46) & 0.49) & 0.50) \\ & 0.12(0.10- & 0.11(0.08- & 0.12(0.10- & 0.12(0.10- & 0.11(0.08- & 0.13(0.10- & 0.15(0.12- & 0.14(0.11- & 0.15(0.12- \\ \text { High } & 0.14) & 0.14) & 0.16) & 0.15) & 0.14) & 0.16) & 0.18) & 0.19) & 0.19)\end{array}$

Depersonalization

$\begin{array}{llllllllll}\text { Low } & \text { Reference } & \text { Reference } & \text { Reference } & \text { Reference } & \text { Reference } & \text { Reference } & \text { Reference } & \text { Reference } & \text { Reference } \\ \text { Mid } & 0.5(0.42- & 0.48(0.37- & 0.51(0.40- & 0.5(0.43- & 0.52(0.41- & 0.47(0.39- & 0.5(0.41- & 0.45(0.34- & 0.53(0.42- \\ & 0.60) & 0.62) & 0.65) & 0.58) & 0.66) & 0.58) & 0.60) & 0.59) & 0.69) \\ & 0.19(0.16- & 0.19(0.14- & 0.18(0.14- & 0.2(0.17- & 0.20(0.15- & 0.20(0.16- & 0.20(0.17- & 0.20(0.15- & 0.20(0.15- \\ \text { High } & 0.22) & 0.24) & 0.23) & 0.24) & 0.25) & 0.25) & 0.24) & 0.26) & 0.25)\end{array}$

Personal accomplishment

\begin{tabular}{llllllllll} 
Low & Reference & Reference & Reference & Reference & Reference & Reference & Reference & Reference & Reference \\
Mid & $2.46(2.09-$ & $2.96(2.29-$ & $2.12(1.71-$ & $1.97(1.69-$ & $2.07(1.62-$ & $1.92(1.57-$ & $2.73(2.29-$ & $3.18(2.43-$ & $2.37(1.87-$ \\
& $2.90)$ & $3.82)$ & $2.64)$ & $2.29)$ & $2.63)$ & $2.35)$ & $3.26)$ & $4.16)$ & $2.99)$ \\
& $5.57(4.51-$ & $6.02(4.42-$ & $5.43(4.06-$ & $3.76(3.16-$ & $3.79(2.91-$ & $3.91(3.08-$ & $6.5(5.12-$ & $6.06(4.36-$ & $7.27(5.13-$ \\
High & $6.88)$ & $8.22)$ & $7.27)$ & $4.48)$ & $4.94)$ & $4.95)$ & $8.24)$ & $8.44)$ & $10.31)$ \\
\hline
\end{tabular}

a. After adjustment for gender, site of practice, age, marital status, education, years of practice, having a leadership role or not, monthly pay, and working hours per week

b. After adjustment for site of practice, age, marital status, education, years of practice, having a leadership role or not, monthly pay, and working hours per week Notes: The Ps values of all results were $<.001$ 
$P<.001$ ), as well as extrinsic factors (OR $0.25,95 \% \mathrm{CI}$ $0.22-0.29, P<.001)$.

\section{Discussion}

Our study was the first nationwide survey that comprehensively investigated the prevalence of burnout and job satisfaction among psychiatrists in China. The sample of $>4000$ psychiatrists, covering all the TPHs in China, represents the largest study of psychiatrist burnout in the literature.

We found a high rate of burnout (38.4\%) among psychiatrists working at TPHs in China. This rate was concordant with those reported in HICs such as the US (36.9\%) [17] and Japan (40.0\%) [42]. More specifically, our study found that $25.4 \%$ of psychiatrists in China had high levels of EE, 32.9\% had high levels of DP, and $20.7 \%$ had low levels of PA. These rates were also consistent with the overall estimated pooled prevalence for high levels of EE, higher levels of DP, and low levels of PA among mental health professionals [43]. There are many causes that may lead to burnout among psychiatrists in China, such as widespread stigma towards mental illness [60], heavy workload [61], low salary [62], and poor physician-patient relationships [63-66]. Interestingly, although the prevalence of burnout among psychiatrists in China is comparable to those in HICs, the percentage of job satisfaction among psychiatrists in China is much lower than those reported in HICs [6769]. For example, $88 \%$ of Australian psychiatrists were satisfied with their work and proud of their profession [69]. In contrast, only $64.4 \%$ of respondents in our study were satisfied with their jobs in general. For those experiencing burnout, the percentage of psychiatrists reporting job satisfaction was even lower (43.2\%). Despite the fact that burnout and job dissatisfaction are closely interrelated, this finding supports the view that burnout and job dissatisfaction are two distinct indicators of job morale with different etiologies [70].

Our study suggests that male psychiatrists in China seem to be at higher risk of burnout and job dissatisfaction. This is inconsistent with the findings from HICs, e.g., the US [39], Austria [71], and France [72]. One possible interpretation is that psychiatrists in China often have to live with unsatisfactory payment [62] and deeprooted stigmatization towards mental health professionals [60], which conflicts with the expectations attached to males in China to gain more wealth and higher status. We also found that early-career psychiatrists reported lower rates of burnout and job dissatisfaction, which was again inconsistent with the findings in North American psychiatrists [39] and European psychiatrists [73]. There may be two explanations. Firstly, because of relatively low tuition costs, medical students in China rarely reply on student loans to finish their medical schools. So, unlike many early-career psychiatrists in HICs, their counterparts in China are often not burdened with medical school debts after graduation and are therefore faced with less financial stress. Indeed, several studies have found strong associations between medical school debts and burnout among early-career physicians [29, 74]. Secondly, most psychiatrists in China start residency training immediately after receiving medical bachelor's degrees, as demonstrated in Table 1 . Therefore, early-career psychiatrists in China are usually much younger than those in many HICs, which makes them to some extent freed from household debts, as well as other family responsibilities.

Till now, there have been an enormous body of evidence suggesting that longer working hours $[72,73,75$, 76] and less control over one's job [39] can lead to burnout and job dissatisfaction. Similarly, our study also reported that longer working hours were significantly associated with both burnout and job dissatisfaction. Regarding job control, it should be noted that our study asked its respondents whether they had leadership roles in their workplaces instead of asking directly how much control they had over their jobs. However, team leaders are often considered to have more control over their jobs. Accordingly, our data suggest that having leadership roles in the workplace was significantly associated with less burnout and more job satisfaction among psychiatrists in China.

It is often reported that psychiatrists have a lower rate of burnout compared with other specialists $[16,17,20]$. Our study also showed a lower rate of burnout (38.4\%) among psychiatrists than those among other specialists, such as neurologists (53.2\%) [77], anesthesiologists (69\%) [49], and oncologists (51\%) [50], in China. There are several possible explanations for this finding. Firstly, psychiatrists may be more aware of their own emotional and psychological needs than other specialists. Also, psychiatrists may be more skilled at stress relieving and have better access to mental health services.

A large body of research has suggested that burnout and job dissatisfaction among health workers is associated with an increased likelihood of leaving their jobs [34-36]. Therefore, a high rate of burnout and job dissatisfaction that we found among psychiatrists in China will evidently complicate the current challenges of workforce development in mental health. In order to mitigate burnout and job dissatisfaction among psychiatrists in China, a systemic strategy attempting to tackle with various factors on different levels is needed [78]. First, on the organizational level, staff care and wellbeing programs, such as mindfulness, stress management, and small group discussions [79], should be developed and provided for psychiatrists. A culture of mutual support should also be created and advocated in mental health 
care facilities [80]. Second, on the national level, new investments should be encouraged in mental health care and particularly for mental health workforce retention. With low salary as an important contributor to job dissatisfaction, the salary and compensation system at psychiatric hospitals needs to be reformed. To better remunerate Chinese psychiatrists, a workload-based salary scheme should be adopted [62]. Finally, on the societal level, it is also of great importance to destigmatize mental health problems and to improve public attitudes towards psychiatry and psychiatrists [81].

Our study had several limitations. First, we utilized self-report measures of burnout and job satisfaction. Although both MBI and MSQ were well validated in China and in other countries, their self-report nature makes their validity still questionable. Second, our study included psychiatrists working in psychiatric hospitals but not those working in other health care settings such as primary care facilities. However, according to the official data from China's National Health Commission, 80.2\% of mental health professionals in China worked in psychiatric hospitals [8]. Therefore, our study can still stand out as being of crucial importance to landscape and investigate burnout and job satisfaction among psychiatrists in China. Third, the cross-sectional survey method does not allow assessment of the direction of effect for the associations described in this study. Future studies are needed to investigate prospectively the effects of relevant factors on psychiatrists' burnout and job dissatisfaction.

\section{Conclusions}

In summary, our study suggested that psychiatrists in China experienced a high rate of burnout and job dissatisfaction. Although the prevalence of burnout among them was similar with those reported in HICs, a much lower rate of job satisfaction was found in psychiatrists in China. Although China's government has made much effort to attract and recruit new psychiatrists since the release of the 2015-2020 National Mental Health Work Plan, our study suggests that at least as much attention should be paid to the crisis of burnout and job satisfaction in psychiatrists in China which will sabotage workforce retention. In order to preserve and strengthen the mental health workforce, proactive measures are urgently needed to mitigate burnout and job dissatisfaction among psychiatrists in China.

\section{Abbreviations}

HIC: high-income country; LMIC: low- and middle-income countries; $\mathrm{SPH}$ : secondary psychiatric hospital; TPH: tertiary psychiatric hospital; MBI-HSS: Maslach Burnout Inventory-Human Service Survey; EE: emotional exhaustion; DP: depersonalization; PA: personal accomplishment; MSQ: Minnesota Satisfaction Questionnaire;
SD: standard deviation; IQR: interquartile range; OR: odds ratio; $\mathrm{Cl}$ : confidence interval

\section{Supplementary Information}

The online version contains supplementary materials available at https://doi. org/10.1186/s12888-021-03568-6.

Additional File 1: Supplementary Table 1. Effects of respondent characteristics on emotional exhaustion, depersonalization, and personal accomplishment measured by the Maslach Burnout Inventory-Human Service Survey in a sample of 4520 psychiatrists in China. Supplementary Table 2. Effects of respondent characteristics on intrinsic and extrinsic job satisfaction measured by the Minnesota Satisfaction Questionnaire in a sample of 4520 psychiatrists in China

\section{Acknowledgements \\ Not applicable.}

\section{Authors' contributions}

$Y T, Y L, F J$ and JZ designed the study and take responsibility for all aspects of it. HY, PW, YC and JZ carried out the data management and analysis. HY and PW wrote the first draft. YT and JZ did the major revision. All the authors provided comments and suggestions and approved the final version.

\section{Funding}

This study was funded by the China's National Health Commission. The funder had no role in study design, data collection, data analysis, data interpretation, or writing of the manuscript.

\section{Availability of data and materials}

Additional data available from the corresponding author at jimingzhu@tsinghua.edu.cn.

\section{Declarations}

Ethical approval and consent to participate

This study was performed in accordance with the Declaration of Helsinki and was approved by the Ethics Committee of Chaohu Hospital of Anhui Medical University (No.201903-kyxm-02). Following a detailed description of the study, an electronic informed consent was obtained from all participants.

\section{Consent for publication}

Not applicable.

\section{Competing interests}

The authors declare that they have no competing interests.

\section{Author details}

'Shanghai Clinical Research Center for Mental Health, Shanghai Key Laboratory of Psychotic Disorders, Shanghai Mental Health Center, Shanghai Jiao Tong University School of Medicine, Shanghai 200030, China. ${ }^{2}$ Vanke School of Public Health, Tsinghua University, Beijing 100084, China. ${ }^{3}$ School of Medicine, Tsinghua University, Beijing 100084, China. ${ }^{4}$ Mental Health Service Line, Atlanta VA Medical Center, Decatur, GA 30033, USA. ${ }^{5}$ Addiction Psychiatry Fellowship Program, Department of Psychiatry and Behavioral Sciences, Emory University, Atlanta, GA 30329, USA. ${ }^{6}$ School of Health Policy and Management, Chinese Academy of Medical Sciences \& Peking Union Medical College, Beijing 100730, China. ${ }^{7}$ Institute for Hospital Management of Tsinghua University, Beijing 100091, China. ${ }^{8}$ Department of Psychiatry, Chaohu Hospital of Anhui Medical University, Hefei 238000, China.

${ }^{9}$ Department of Psychiatry, Anhui Psychiatric Center, Anhui Medical University, Hefei, China. ${ }^{10}$ School of International and Public Affairs, Shanghai Jiao Tong University, Shanghai, China. 
Received: 19 June 2021 Accepted: 26 October 2021

Published online: 24 November 2021

\section{References}

1. Phillips MR, Zhang J, Shi Q, Song Z, Ding Z, Pang S, et al. Prevalence, treatment, and associated disability of mental disorders in four provinces in China during 2001-05: an epidemiological survey. Lancet. 2009;373(9680): 2041-53. https://doi.org/10.1016/S0140-6736(09)60660-7.

2. Charlson FJ, Baxter AJ, Cheng HG, Shidhaye R, Whiteford HA. The burden of mental, neurological, and substance use disorders in China and India: a systematic analysis of community representative epidemiological studies. Lancet. 2016;388(10042):376-89. https://doi.org/10.1016/S0140-6736(16)3 0590-6.

3. Huang Y, Wang Y, Wang H, Liu Z, Yu X, Yan J, et al. Prevalence of mental disorders in China: a cross-sectional epidemiological study. Lancet Psychiatry. 2019;6(3):211-24. https://doi.org/10.1016/S2215-0366(18)30511-X.

4. Qiu J, Shen B, Zhao M, Wang Z, Xie B, Xu Y. A nationwide survey of psychological distress among Chinese people in the COVID-19 epidemic: implications and policy recommendations. Gen Psych. 2020;33(2):e100213. https://doi.org/10.1136/gpsych-2020-100213.

5. Huang $Y$, Zhao N. Chinese mental health burden during the COVID-19 pandemic. Asian J Psychiatr. 2020;51:102052. https://doi.org/10.1016/j.ajp.202 0.102052 .

6. Li J, Yang Z, Qiu H, Wang Y, Jian L, Ji J, et al. Anxiety and depression among general population in China at the peak of the COVID-19 epidemic. World Psychiatry. 2020;19(2):249-50. https://doi.org/10.1002/wps.20758.

7. Xu J, Wang J, Wimo A, Qiu C. The economic burden of mental disorders in China, 2005-2013: implications for health policy. BMC Psychiatry. 2016;16(1): 137. https://doi.org/10.1186/s12888-016-0839-0.

8. Shi C, Ma N, Wang L, Yi L, Wang X, Zhang W, et al. Study of the mental health resources in China. Chinese J Health Policy. 2019;12:51-7.

9. Xiang Y-T, Yu X, Sartorius N, Ungvari GS, Chiu HF. Mental health in China: challenges and progress. Lancet. 2012;380(9855):1715-6. https://doi.org/10.1 016/S0140-6736(11)60893-3.

10. Liang D, Mays VM, Hwang W-C. Integrated mental health services in China: challenges and planning for the future. Health Policy Plan. 2018;33(1):10722. https://doi.org/10.1093/heapol/czX137.

11. XIONG W, PHILLIPS MR. Translated and annotated version of the 2015-2020 National Mental Health Work Plan of the People's republic of China. Shanghai Arch Psychiatry. 2016;28(1):4-17. https://doi.org/10.11919/j.issn.1 002-0829.216012.

12. Zhang $Y$, Feng $X$. The relationship between job satisfaction, burnout, and turnover intention among physicians from urban state-owned medical institutions in Hubei, China: a cross-sectional study. BMC Health Serv Res. 2011;11(1):235. https://doi.org/10.1186/1472-6963-11-235.

13. Jiang F, Hu L, Rakofsky J, Liu T, Wu S, Zhao P, et al. Sociodemographic characteristics and job satisfaction of psychiatrists in China: results from the first Nationwide survey. PS. 2018;69(12):1245-51. https://doi.org/10.1176/a ppi.ps.201800197.

14. WHO. Burn-out an "occupational phenomenon": International Classification of Diseases. World Health Organization; 2019. https://www.who.int/news/ item/28-05-2019-burn-out-an-occupational-phenomenon-international-cla ssification-of-diseases. Accessed 30 Sept 2021.

15. Maslach C, Leiter MP. New insights into burnout and health care: strategies for improving civility and alleviating burnout. Med Teach. 2017;39(2):160-3. https://doi.org/10.1080/0142159X.2016.1248918.

16. Shanafelt TD, Hasan O, Dyrbye LN, Sinsky C, Satele D, Sloan J, et al. Changes in burnout and satisfaction with work-life balance in physicians and the general US working population between 2011 and 2014. Mayo Clin Proc. 2015;90(12):1600-13. https://doi.org/10.1016/j.mayocp.2015.08.023.

17. Shanafelt TD, West CP, Sinsky C, Trockel M, Tutty M, Satele DV, et al. Changes in burnout and satisfaction with work-life integration in physicians and the general US working population between 2011 and 2017. Mayo Clin Proc. 2019;94(9):1681-94. https://doi.org/10.1016/j.mayocp.2018.10.023.

18. Bhatnagar G. Physician burnout. Lancet. 2020;395(10221):333. https://doi. org/10.1016/S0140-6736(19)32612-1.

19. West CP, Dyrbye LN, Shanafelt TD. Physician burnout: contributors, consequences and solutions. J Intern Med. 2018;283(6):516-29. https://doi. org/10.1111/joim.12752.

20. Shanafelt TD, Boone S, Tan L, Dyrbye LN, Sotile W, Satele D, et al. Burnout and satisfaction with work-life balance among US physicians relative to the general US population. Arch Intern Med. 2012;172(18):1377-85. https://doi org/10.1001/archinternmed.2012.3199.

21. Campbell DA, Sonnad SS, Eckhauser FE, Campbell KK, Greenfield LJ. Burnout among American surgeons. Surgery. 2001;130(4):696-702; discussion 702705. https://doi.org/10.1067/msy.2001.116676.

22. Bertges Yost W, Eshelman A, Raoufi M, Abouljoud MS. A national study of burnout among American transplant surgeons. Transplant Proc. 2005;37(2): 1399-401. https://doi.org/10.1016/j.transproceed.2005.01.055.

23. Dyrbye LN, West CP, Satele D, Sloan JA, Shanafelt TD. Work/home conflict and burnout among academic internal medicine physicians. Arch Intern Med. 2011;171(13):1207-9. https://doi.org/10.1001/archinternmed.2011.289.

24. Dyrbye LN, Shanafelt TD, Balch CM, Satele D, Sloan J, Freischlag J. Relationship between work-home conflicts and burnout among American surgeons: a comparison by sex. Arch Surg. 2011;146(2):211-7. https://doi. org/10.1001/archsurg.2010.310.

25. Kuerer HM, Eberlein TJ, Pollock RE, Huschka M, Baile WF, Morrow M, et al. Career satisfaction, practice patterns and burnout among surgical oncologists: report on the quality of life of members of the Society of Surgical Oncology. Ann Surg Oncol. 2007;14(11):3043-53. https://doi.org/1 0.1245/s10434-007-9579-1.

26. Shanafelt TD, Balch CM, Bechamps GJ, Russell T, Dyrbye L, Satele D, et al. Burnout and career satisfaction among American surgeons. Ann Surg. 2009; 250(3):463-71. https://doi.org/10.1097/SLA.0b013e3181ac4dfd.

27. Freeborn DK. Satisfaction, commitment, and psychological well-being among HMO physicians. West J Med. 2001;174(1):13-8. https://doi.org/1 0.1136/ewjm.174.1.13

28. Shanafelt TD, Oreskovich MR, Dyrbye LN, Satele DV, Hanks JB, Sloan JA, et al Avoiding burnout: the personal health habits and wellness practices of US surgeons. Ann Surg. 2012;255(4):625-33. https://doi.org/10.1097/SLA.0b013 e31824b2faO

29. West CP, Shanafelt TD, Kolars JC. Quality of life, burnout, educational debt, and medical knowledge among internal medicine residents. JAMA. 2011; 306(9):952-60. https://doi.org/10.1001/jama.2011.1247.

30. Patel RS, Bachu R, Adikey A, Malik M, Shah M. Factors Related to Physician Burnout and Its Consequences: A Review. Behav Sci (Basel). 2018;8(11):98.

31. Menon NK, Shanafelt TD, Sinsky CA, Linzer M, Carlasare L, Brady KJS, et al. Association of Physician Burnout with Suicidal Ideation and Medical Errors. JAMA Netw Open. 2020;3(12):e2028780-0. https://doi.org/10.1001/jama networkopen.2020.28780.

32. Chen $\mathrm{K}-\mathrm{Y}$, Yang C-M, Lien C-H, Chiou H-Y, Lin M-R, Chang H-R, et al. Burnout, job satisfaction, and medical malpractice among physicians. Int J Med Sci. 2013;10(11):1471-8. https://doi.org/10.7150/ijms.6743.

33. Shanafelt TD, Balch CM, Bechamps G, Russell T, Dyrbye L, Satele D, et al. Burnout and medical errors among American surgeons. Ann Surg. 2010; 251(6):995-1000. https://doi.org/10.1097/SLA.0b013e3181bfdab3.

34. Aiken LH, Clarke SP, Sloane DM, Sochalski J, Silber JH. Hospital nurse staffing and patient mortality, nurse burnout, and job dissatisfaction. JAMA. 2002; 288(16):1987-93. https://doi.org/10.1001/jama.288.16.1987.

35. Shanafelt TD, Raymond M, Kosty M, Satele D, Horn L, Pippen J, et al. Satisfaction with work-life balance and the career and retirement plans of US oncologists. J Clin Oncol. 2014;32(11):1127-35. https://doi.org/10.1200/ JCO.2013.53.4560.

36. Pantenburg $\mathrm{B}$, Luppa $\mathrm{M}$, König $\mathrm{H}-\mathrm{H}$, Riedel-Heller SG. Burnout among young physicians and its association with physicians' wishes to leave: results of a survey in Saxony. Germany J Occup Med Toxicol. 2016;11(1):2. https://doi. org/10.1186/s12995-016-0091-z.

37. Kumar S. Burnout in psychiatrists. World Psychiatry. 2007;6(3):186-9.

38. Bressi C, Porcellana M, Gambini O, Madia L, Muffatti R, Peirone A, et al. Burnout among psychiatrists in Milan: a multicenter survey. Psychiatr Serv. 2009;60(7):985-8. https://doi.org/10.1176/ps.2009.60.7.985.

39. Summers RF, Gorrindo T, Hwang S, Aggarwal R, Guille C. Well-Being, Burnout, and Depression Among North American Psychiatrists: The State of Our Profession. Am J Psychiatry. 2020;177(10):955-64.

40. Kumar S, Fischer J, Robinson E, Hatcher S, Bhagat RN. Burnout and job satisfaction in New Zealand psychiatrists: a national study. Int J Soc Psychiatry. 2007;53(4):306-16. https://doi.org/10.1177/0020764006074534.

41. Kumar S. Burnout and psychiatrists: what do we know and where to from here. Epidemiol Psychiatr Sci. 2011;20(4):295-301. https://doi.org/10.1017/S2 04579601100059X

42. Tateno M, Jovanović N, Beezhold J, Uehara-Aoyama K, Umene-Nakano W, Nakamae T, et al. Suicidal ideation and burnout among psychiatric trainees 
in Japan. Early Interv Psychiatry. 2018;12(5):935-7. https://doi.org/10.1111/ eip.12466.

43. O'Connor K, Muller Neff D, Pitman S. Burnout in mental health professionals: a systematic review and meta-analysis of prevalence and determinants. Eur Psychiatry. 2018;53:74-99. https://doi.org/10.1016/j.eurpsy.2018.06.003.

44. Yu W, Li M, Nong X, Ding T, Ye F, Liu J, et al. Practices and attitudes of doctors and patients to downward referral in Shanghai. China BMJ Open. 2017;7(4):e012565. https://doi.org/10.1136/bmjopen-2016-012565.

45. Zhang W, Li X, Lin Y, Zhang X, Qu Z, Wang X, et al. Pathways to psychiatric care in urban North China: a general hospital based study. Int J Ment Heal Syst. 2013;7(1):22. https://doi.org/10.1186/1752-4458-7-22.

46. Hu Y, Zhang Z. Skilled doctors in tertiary hospitals are already overworked in China. Lancet Glob Health. 2015;3(12):e737. https://doi.org/10.1016/ S2214-109X(15)00192-8.

47. Zhang C, Hu L, Ma J, Wu S, Guo J, Liu Y. Factors determining intention to leave among physicians in tertiary hospitals in China: a national crosssectional study. BMJ Open. 2019;9(3):e023756. https://doi.org/10.1136/ bmjopen-2018-023756.

48. Maslach C, Jackson SE, Leiter MP. Maslach burnout inventory: third edition. In: Evaluating stress: a book of resources. Lanham, MD, US: Scarecrow Education; 1997. p. 191-218.

49. Li H, Zuo M, Gelb AW, Zhang B, Zhao X, Yao D, et al. Chinese anesthesiologists have high burnout and low job satisfaction: a crosssectional survey. Anesth Analg. 2018;126(3):1004-12. https://doi.org/1 $0.1213 /$ ANE.0000000000002776

50. Ma S, Huang Y, Yang Y, Ma Y, Zhou T, Zhao H, et al. Prevalence of burnout and career satisfaction among oncologists in China: a National Survey. Oncologist. 2019;24(7):e480-9. https://doi.org/10.1634/theoncologist.20180249 .

51. Zheng H, Shao H, Zhou Y. Burnout among Chinese adult reconstructive surgeons: incidence, risk factors, and relationship with intraoperative irritability. J Arthroplast. 2018;33(4):1253-7. https://doi.org/10.1016/j.arth.201 7.10.049.

52. Thomas NK. Resident burnout. JAMA. 2004;292(23):2880-9. https://doi.org// 0.1001/jama.292.23.2880.

53. Dyrbye LN, West CP, Shanafelt TD. Defining burnout as a dichotomous variable. J Gen Intern Med. 2009;24(3):440; author reply 441. https://doi. org/10.1007/s11606-008-0876-6

54. Shanafelt TD, Bradley KA, Wipf JE, Back AL. Burnout and self-reported patient care in an internal medicine residency program. Ann Intern Med. 2002;136(5):358-67. https://doi.org/10.7326/0003-4819-136-5-20020305000008.

55. Schaufeli WB, Bakker AB, Hoogduin K, Schaap C, Kladler A. On the clinical validity of the maslach burnout inventory and the burnout measure. Psychol Health. 2001;16(5):565-82. https://doi.org/10.1080/088704401084 05527.

56. Wang J, Zhao Q, Yuan L, Pan Z. Survey on work satisfaction among general practitioners in Shanghai. Chinese J Gen Pract. 2017;16:921-5.

57. Liu Z, Wei W, Wang L, Cui H, Li Y, Zhang F. The relationship among job satisfaction,work engagement and organizational citizenship behavior of nurses. Chin J Behav Med Brain Sci. 2017:26:747-50.

58. Xiao Y, Wang J, Chen S, Wu Z, Cai J, Weng Z, et al. Psychological distress, burnout level and job satisfaction in emergency medicine: a cross-sectional study of physicians in China. Emerg Med Australas. 2014;26(6):538-42. https://doi.org/10.1111/1742-6723.12315.

59. Spector P. Job satisfaction: application. Causes, and Consequences. Thousand Oaks, California: Assessment; 1997. https://doi.org/10.4135/97814 52231549 .

60. Yin H, Wardenaar K, Xu G, Tian H, Schoevers RA. Mental health stigma and mental health knowledge in Chinese population: a cross-sectional study. BMC Psychiatry. 2020;20(1):323. https://doi.org/10.1186/s12888-020-02705-x.

61. Fu Y, Schwebel DC, Hu G. Physicians' workloads in China: 1998-2016. Int J Environ Res Public Health. 2018;15(8). https://doi.org/10.3390/ijerph1508164 9.

62. Zhang C, Liu Y. The salary of physicians in Chinese public tertiary hospitals: a national cross-sectional and follow-up study. BMC Health Serv Res. 2018; 18(1):661. https://doi.org/10.1186/s12913-018-3461-7.

63. Lancet T. Violence against doctors: why China? Why now? What next. Lancet. 2014;383(9922):1013. https://doi.org/10.1016/S0140-6736(14)60501-8.

64. Wu D, Wang Y, Lam KF, Hesketh $T$. Health system reforms, violence against doctors and job satisfaction in the medical profession: a cross-sectional survey in Zhejiang Province. Eastern China BMJ Open. 2014;4(12):e006431. https://doi.org/10.1136/bmjopen-2014-006431.

65. Cai R, Tang J, Deng C, Lv G, Xu X, Sylvia S, et al. Violence against health care workers in China, 2013-2016: evidence from the national judgment documents. Hum Resour Health. 2019;17(1):103. https://doi.org/10.1186/s12 960-019-0440-y.

66. Shi J, Wang S, Zhou P, Shi L, Zhang Y, Bai F, et al. The frequency of patientinitiated violence and its psychological impact on physicians in China: a cross-sectional study. PLoS ONE. 2015;10(6):e0128394. https://doi.org/10.13 71/journal.pone.0128394.

67. Baumgardt J, Moock J, Rössler W, Kawohl W. Aspects of sustainability: cooperation, job satisfaction, and burnout among Swiss psychiatrists. Front Public Health. 2015;3. https://doi.org/10.3389/fpubh.2015.00025.

68. Heponiemi T, Aalto A-M, Puttonen S, Vänskä J, Elovainio M. Work-related stress, job resources, and well-being among psychiatrists and other medical specialists in Finland. Psychiatric Serv (Washington, DC). 2014;65:796-801.

69. Rey JM, Walter G, Giuffrida M. Australian psychiatrists today: proud of their profession but stressed and apprehensive about the future. Aust N Z J Psychiatry. 2004;38(3):105-10. https://doi.org/10.1080/j.1440-1614.2004.0132 0.x.

70. Sabitova A, McGranahan R, Altamore F, Jovanovic N, Windle E, Priebe S. Indicators associated with job morale among physicians and dentists in low-income and middle-income countries: a systematic review and Metaanalysis. JAMA Netw Open. 2020;3(1):e1913202. https://doi.org/10.1001/jama networkopen.2019.13202.

71. Rössler W. Stress, burnout, and job dissatisfaction in mental health workers. Eur Arch Psychiatry Clin Neurosci. 2012;262(Suppl 2):S65-9. https://doi.org/1 0.1007/s00406-012-0353-4.

72. Nuss P, Tessier C, Masson M, Fossati P, Gaillard R, Lapidus N, et al. Factors associated with a higher score of burnout in a population of 860 French psychiatrists. Front Psychiatry. 2020;11:371. https://doi.org/10.3389/fpsyt.202 0.00371.

73. Jovanović N, Podlesek A, Volpe U, Barrett E, Ferrari S, Rojnic Kuzman M, et al. Burnout syndrome among psychiatric trainees in 22 countries: risk increased by long working hours, lack of supervision, and psychiatry not being first career choice. Eur Psychiatry. 2016;32:34-41. https://doi.org/10.1 016/.j.eurpsy.2015.10.007.

74. Pisaniello MS, Asahina AT, Bacchi S, Wagner M, Perry SW, Wong M-L, et al. Effect of medical student debt on mental health, academic performance and specialty choice: a systematic review. BMJ Open. 2019;9(7):e029980. https://doi.org/10.1136/bmjopen-2019-029980.

75. Chan MK, Chew QH, Sim K. Burnout and associated factors in psychiatry residents: a systematic review. Int J Med Educ. 2019;10:149-60. https://doi. org/10.5116/ijme.5d21.b621.

76. Nimmawitt N, Wannarit K, Pariwatcharakul P. Thai psychiatrists and burnout: a national survey. PLoS ONE. 2020;15(4):e0230204. https://doi.org/10.1371/ journal.pone.0230204.

77. Zhou X, Pu J, Zhong X, Zhu D, Yin D, Yang L, et al. Burnout, psychological morbidity, job stress, and job satisfaction in Chinese neurologists. Neurology. 2017;88(18):1727-35. https://doi.org/10.1212/WNL. 0000000000003883

78. Medicine NA of, National Academies of Sciences, Engineering, and Medicine. Taking Action Against Clinician Burnout: A Systems Approach to Professional Well-Being. Washington, DC: The National Academies Press; 2019. https://doi.org/10.17226/25521

79. West CP, Dyrbye LN, Erwin PJ, Shanafelt TD. Interventions to prevent and reduce physician burnout: a systematic review and meta-analysis. Lancet. 2016;388(10057):2272-81. https://doi.org/10.1016/S0140-6736(16)31279-X.

80. Zeller EL, Doutrich D, Guido GW, Hoeksel R. A culture of mutual support: discovering why new nurses stay in nursing. J Contin Educ Nurs. 2011;42(9): 409-14. https://doi.org/10.3928/00220124-20110615-02.

81. Bhugra D, Sartorius N, Fiorillo A, Evans-Lacko S, Ventriglio A, Hermans MHM, et al. EPA guidance on how to improve the image of psychiatry and of the psychiatrist. Eur Psychiatry. 2015;30(3):423-30. https://doi.org/10.1016/j. eurpsy.2015.02.003.

\section{Publisher's Note}

Springer Nature remains neutral with regard to jurisdictional claims in published maps and institutional affiliations. 